\title{
Lack of vitamin D and other stories ...
}

Homo sapiens probably reached Ulm in southern Germany around 40000 years ago, when the area offered plenty of good mammoth hunting on the steppe between the Alpine ice mass immediately to the south and the endless glacier that covered Europe from about Hamburg northwards. The human population of Ulm has changed a great deal since then, but one ancient feature remains-Ulmians, like most people in Europe, are bad at making vitamin D. In a study of 1418 older people living in southern Germany, researchers investigated the seasonal differences in vitamin D levels (Age and Ageing 2013; doi:10. 1093/ageing/aft042). They found that proportions of vitamin D deficiency, insufficiency, and sufficiency were $78.8 \%, 19.2 \%$, and $1.9 \%$ in March 2009, respectively. Corresponding proportions in August 2009 were 16.1\%, 63.4\%, and 20.5\%, respectively. Now that their supply of mammoth liver has dried up, the people of Ulm may need to look to other sources to remedy their lack of vitamin $\mathrm{D}$.

Acute pancreatitis is often triggered by alcohol consumption, and if that is the case, patients are advised to abstain for life. This doleful sentence is sometimes ignored, but alas it should not be. A study in Alcohol and Alcoholism (2013; doi:10.1093/ alcalc/agt019) followed up 118 patients after a first episode of alcohol related pancreatitis. Only 18 patients (all men) fulfilled the criteria for total abstinence, and none of them had recurrence over a mean of five years. Of the remaining patients, more than a third had at least one episode of recurrent pancreatitis during follow-up.

Palliative care for cancer grew up without an evidence base: it simply went ahead and used what was known to work. And whenever any disease is reaching its end stage, and we can do nothing to alter its course, then what we should be offering is the best palliative treatment we can devise. There is shamefully little research to guide us in non-cancer palliation, but in any case, our dying patients can't wait for it. Take, for example, advanced chronic obstructive pulmonary disease. A descriptive study of opioid use for breathlessness in CMAJ Open (2013;1:E27-36, doi:10.9778/cmajo.20120031) may fall well short of the gold standard in this field, which would be a meta-analysis of n-of- 1 trials. But the study tells you that most patients found opioids helpful, and that small differences brought big gains.

\begin{abstract}
A few thin children in the Dutch hunger winter of 1944-45 seemed to do better when deprived of bread by the Nazi occupiers. Thereafter, coeliac disease came to be recognised as an uncommon cause of paediatric disease, brought about by wheat gluten. Adults then gradually joined the ranks of those diagnosed with coeliac disease, at the rate of about one in 5000 . But when serological testing arrived, it turned out that the true incidence of gluten autoimmunity was one in 100. A study of a paediatric referral centre in south Wales shows that coeliac disease now presents "typically" with gastrointestinal symptoms in a minority of children only (Archives of Disease in Childhood 2013, doi:10.1136/archdischild-2012-303113). Looking at the epidemiology of the condition over 28 years, researchers found that many children were asymptomatic and discovered incidentally, and $90 \%$ were not discovered at all.
\end{abstract}

Mortals, take heed! You are all in a state of pre-death, and the only remedy is to keep calm and carry on. Minerva reserves a special kind of divine anger for those who label people with pre-diseases for which there is no useful intervention. Screening for dementia is foolish. If you feel you are losing your marbles, you may be right, but there is nobody who can give them back to you. Nonetheless, there are contexts where it may be useful to measure the degree of dementia. Of the various scores available, the mini-Kingston Standardized Cognitive Assessment seems practical and well validated - and is free to download (American Journal of Alzheimer's Disease and Other Dementias 2013, doi:10.1177/1533317513481095).

Men are from Mars, and women are from Venus? Fiddlesticks. Yet it is true that men don't really "get" us a lot of the time. They look you in the eye and then say something really stupid. A study of functional magnetic resonance imaging in 22 participants suggests that this is scientifically true (PLOS One 2013;8:e60278, doi:10.1371/journal.pone.0060278). According to the authors: "We found that men actually had twice as many problems in recognizing emotions [as women], and that these problems were particularly associated with a lack of activation in limbic regions of the brain." So chaps, just shut it: if you need something to say, just tell me how pretty I look in my helmet.

Cite this as: BMJ 2013;346:f2530

๑ BMJ Publishing Group Ltd 2013 